form $A \wedge A D E$ ENISK

\title{
form
}

Vol I4, $\mathrm{No}_{2}(2 \mathrm{O} 2 \mathrm{I})$

\section{Reimagining lace in a digital space}

\section{An interdisciplinary collaboration between an animation artist and a textile designer}

\begin{abstract}
This paper presents how a contemporary lace practice explored the medium of animation as a digital tool for craft research. Research is practice based and theoretically framed around notions of smooth and striated space as a means to articulate how a designer engages in textile thinking to reimagine new expressions for (p)lace in a digital age. The author sought to test out if animation could capture and disseminate an ephemeral lace process. This led to a curious convergence between two disciplines. What was initially to be a tool for efficiency and speed unexpectedly turned out to be a method for abstracting an allusive lace making process. Learning about the idiosyncrasies of another discipline opened new aesthetic opportunities for a contemporary lace practice and introduced novel methods to disseminate future material research.
\end{abstract}

Keywords:

Contemporary Lace, Materiality, Animation, (P)lace-making, Lace-scape

\section{INTRODUCTION}

The following interdisciplinary collaboration between a textile designer Cecilia Heffer and animation artist Damian Gascoigne aims to share how the medium of animation brought new thinking into a contemporary lace practice. The collaboration is analysed from the perspective of a textile designer who sought out animation as a tool to share the nuances of an ephemeral lace making process. The exchange began to illicit a novel working methodology whereby both parties learnt from each other's disciplines. The first half of the paper introduces Heffer's alternative lace making process which explores an artistic reinterpretation of a site/landscape through disruptive patterning and machine stitching. Stitching is theoretically framed as a gestural form of line and knowledge making (Ingold, 2007); through a methodology identified as textile thinking (Igoe, 2013). The second half shares the findings from the collaboration. 

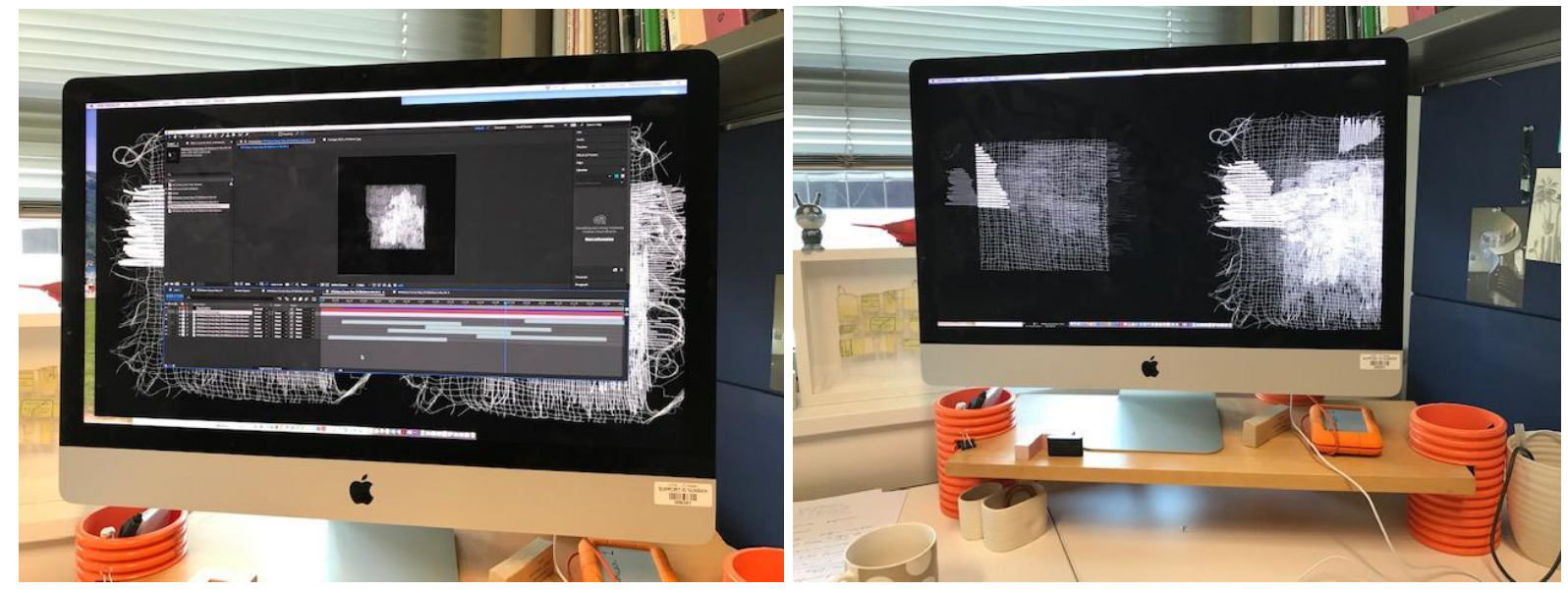

FIGURE 1 AND 2. Programming opacity and rotation of lace samplers (figure 1). Reviewing the effects created through layering, angles of rotation, movement/speed (figure 2). Photo taken by author.

\section{The dissemination of craft thinking/ a gap in the field/community of practice}

Currently there is a gap of knowledge in craft research practice with regard to contemporary lace making. While extensive literature is available on historical lace and lace making manuals, little reflective in-depth critique exists on contemporary lace as it is a relatively recent addition to the field (Orpin, 2015, p.68). This paper consequently seeks to share the discoveries that emerged from a unique interdisciplinary collaboration between a textile designer and animation artist as a means to open up new pathways for future creative research while at the same time present a novel expression of ( $p$ )lace in a digital age.

Finding meaningful ways to disseminate the thinking and making procedures in craft research to broader interdisciplinary fields is particularly critical for the genre of lace making as it is potentially in danger of being relegated to a museum archive or viewed solely as an applied art (Pajaczkowska, 2016, p.92). In recent years, key handbooks on textile theory and culture seek to 'make known' the tacit knowledge embodied in material research practice (Hemmings, 2012; Jefferies et al., 2016). The conscious decision making textile designers action through their material process is identified as textile thinking (Igoe, 2013; Lean, 2020). It involves a co-evolutionary thinking and making process unique to the discipline which can extend to broader design fields.

Heffer carefully explores the boundaries of her chosen medium (Lace) in a designerly way, by using elements of its definition as variables to create contemporary varieties - always radically changing some variables, but never too many (Ward, 2012). Thus, she is not just borrowing particular qualities of lace for use in another context (e.g., making a graphic pattern into a print) but exploring how the concept of lace itself can be expanded (Dorst, 2007). Through these explorations, she has discovered new connections to other fields within and beyond the designing disciplines (Dorst, 2015).

The research is situated in an interdisciplinary community of practice which is exploring what it means to craft textiles in a digital age (Nimkulrat, Kane \& Walton, 2016, p.3). Heffer's contemporary lace practice responds to digital advances in the field as a means to explore new expressions for lace design that offer a closer reflection of the social concerns of our modern world (Shepherd, 2011, p.9). As such it contributes to a genre of contemporary modern lacemaking that has emerged over the last decade through inaugural international lace exhibitions such as Radical Lace 2008, Lost in Lace 2011 and Love Lace 2011 and the recent Lace not Lace: Contemporary Fiber Art from Lace Making Techniques 2019. Interest in this genre continues to grow as evidenced by an emerging community of practice who are exploring the materiality of lace in different ways. Of particular interest to Heffer's research is the practice of artists such as Joy Buttress who explores lace materialities through digital video work inspired by archival lace from the Newstead Abbey Lace Collection (Lace Unveiled Exhibition, Nottingham 2018). Historian and lace artist Angharad Rixon who leads contemporary lace initiatives such as the Doily Free 
Zone. Japanese textile innovator Reiko Sudo who considers lace making through the philosophy of Ma whereby agency is given to the gaps and spaces of emptiness in between materialities (Sudo, 2011, p.100).

\section{Background to the collaboration: seeking to share an ephemeral lace process}

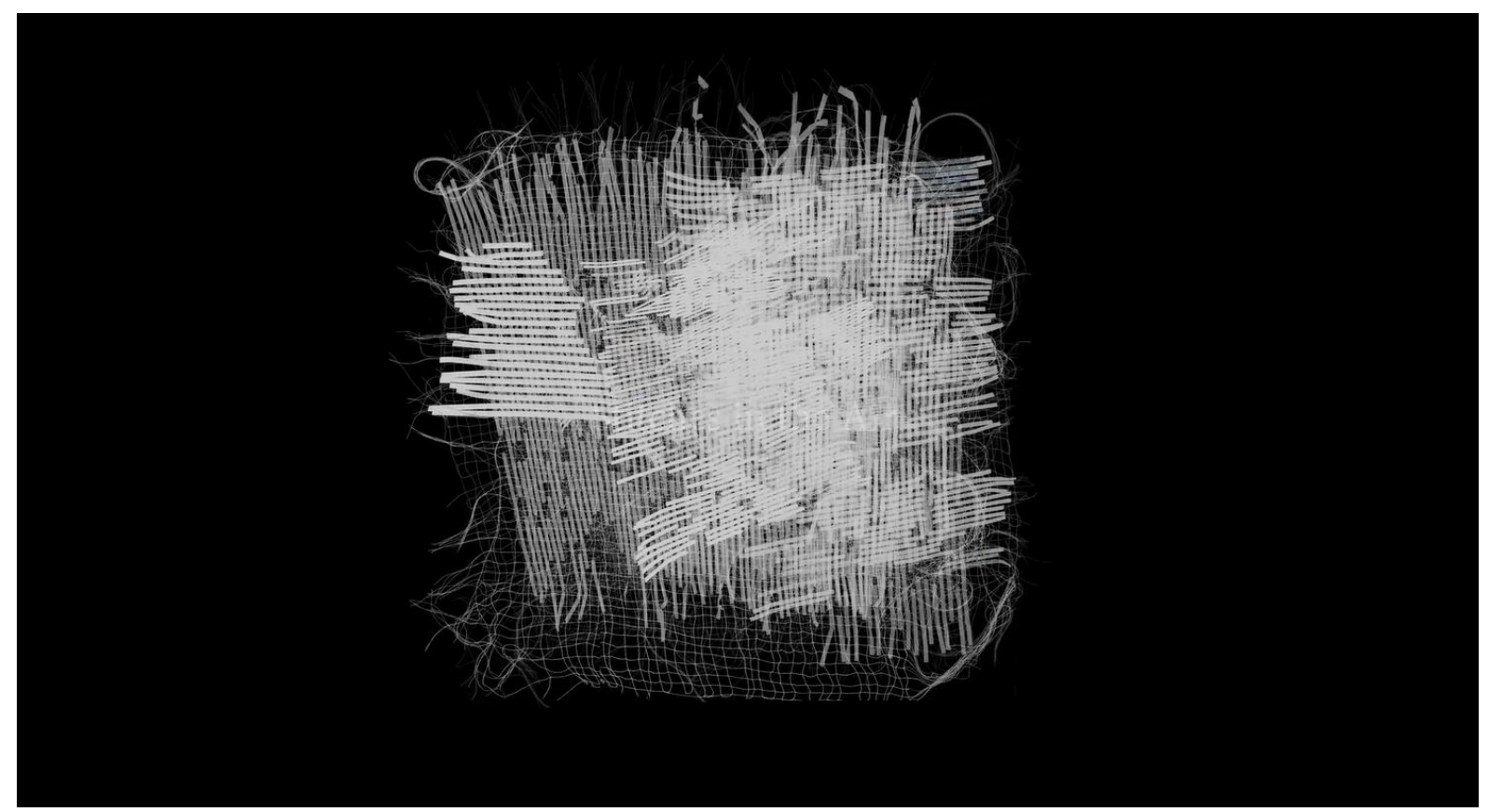

FIGURE 3. Video: Stitches in the Air. To watch the video, click the picture

The collaboration took place over a course of a year in 2019 firstly as an open-ended research conversation where both parties were curious about the new aesthetic opportunities that could potentially arise if a contemporary lace practice were to converge with the discipline of animation. Out of these conversations Heffer could see an opportunity to explore a problem she had encountered in attempting to share with viewers what is essentially an ephemeral lace process. The creation of a lace for example involves various stages of metamorphosis which involve incremental decisions at the time of making, these can be quite subtle and hard to articulate yet are implicit to craft innovation. Viewers consistently question how the lace is made. A simple enough question however one that is complex if designers are to move beyond a purely technical response to include making as a cultural and social issue (Sennett, 2008 , p.8). Heffer found that her answers seemed to fall short in sharing the complex tacit knowledge implicit in the lace process which is where the research lies. This led to alternative publishing models such as Lace Narratives: A Monograph, 2005 - 2015 and a process film/interview titled Drawn Threads (see Figure 4). The monograph and film developed out of an interdisciplinary collaboration with Visual Communication researcher Dr Zoe Sadokierski and film maker Dr Chris Caines. It now serves as a window for designers and students into the reflective thinking behind an otherwise private contemporary lace making practice (Heffer, 2015). 


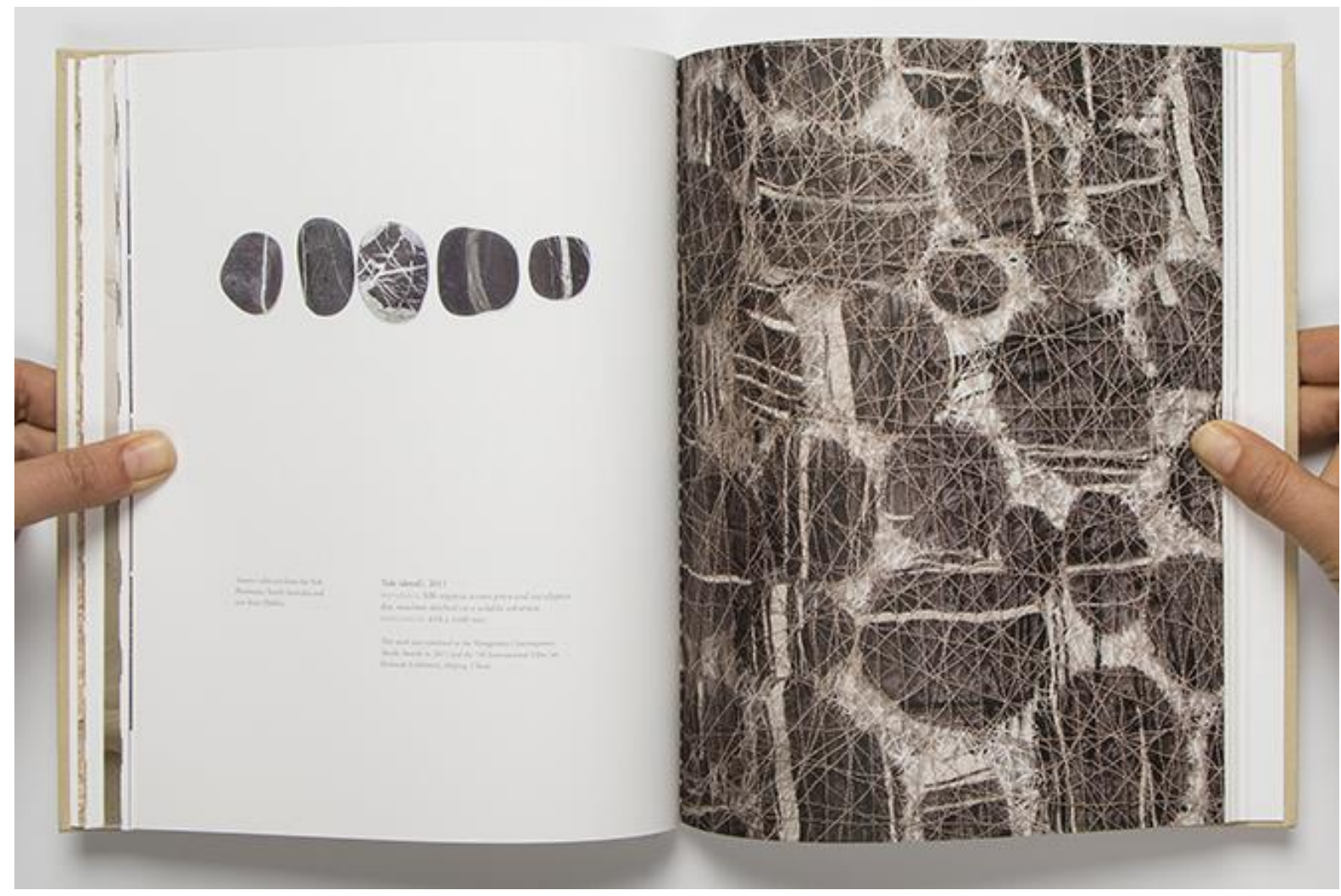

FIGURE 4. Publishing Craft Research, Lace Narratives: A Monograph, 2005 - 2015. Photo credit Jackson Mann.

Heffer's ongoing enquiry into exploring alternative ways to disseminate craft research has led to her current work with Gascoigne. The collaboration unfolded seamlessly over regular meetings in which they viewed how machine stitched lace samplers performed through an animation program known as Effects (see Figures 5 and 6). The outcome of this work produced a suite of tests and a film titled 'stitches in the air' a direct reference to historical embroidered laces known as "punto in aire" (Plumley, 2012, p.63). As short films, the animations now serve as a record bank of material data for the author to reenter and observe the subtle material nuances that often go unnoticed in the making process (Mason, 2002, p.57).

As a result of these experiments the author discovered that animation moved beyond serving as a digital tool for speed and efficiency to becoming a method for abstracting the craft of lace making (Carnie, 2007, p.20). Animation introduced movement and three-dimensionality to the lace which created an intriguing phenomenon to a textile that is normally viewed as a two-dimensional surface. The animation offers a new spatial territory, whereby the viewer is able to experience an embodied sense of transience through a material lace liminality which is continually moving, unravelling and coming into being (Wilson, 2008). It enables the viewer to take a visual and mental journey through moving data-lace assemblages which appear to cascade in a type of dissolving scaffolding. Their constantly moving formations seem to be suspended in an endless state of continual renewal. How viewers respond to the film is open to interpretation however the film offers a dimensional shift from the traditional experience/perception of lace as a decorative fashion or interior textile to one that is visually and conceptually engaging in a novel evocative way. 

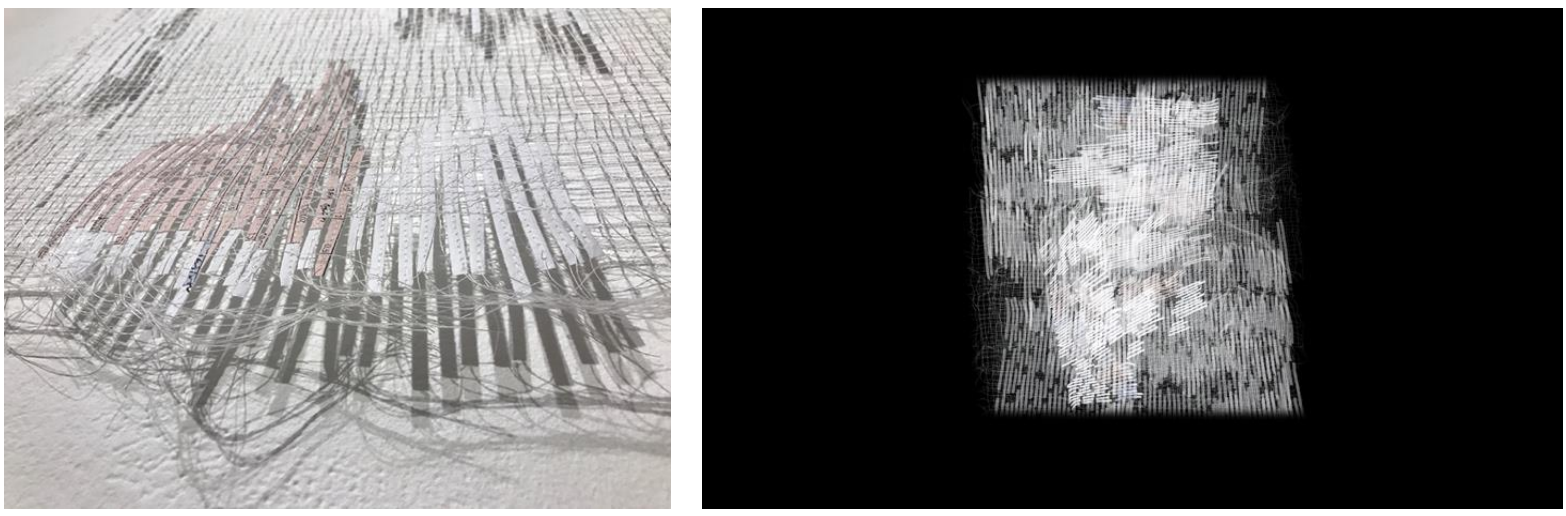

FIGURE 5 AND 6. Detail of Data Lace sampler (figure 4). Screen grab of Data Lace animation (figure 5). Photo taken by author.

\section{EXPLORING RELATIONSHIPS BETWEEN TEXTILE MAKING AND (P)LACE Research Theme and Methods}

The following sections reflects on how Heffer engages with designerly textile thinking to explore alternative making methods for ( $p$ )lace-marking. This is framed through the work of Anthropologist Tim Ingold's notion of the line as a form of gesture and knowledge making. Lace structures are explored as metaphor for ( $p$ )lace marking through theories of smooth and striated space (Deleuze, Guattari 1987). The terms ( $p$ )lace and lace-scape throughout refer to the construction of a lace surface as a material terrain whereby material innovation is explored as a means to respond to the world around us. In this regard, a lace surface serves as a textile research site whereby new expressions for contemporary cultural place marking are explored and tested.

What are the new place markers of our times? Traditionally lace has served as a place marker through the materials, techniques and motifs employed to produce it (Briggs-Goode, Dean, 2014, p.7). Today however our relationship with place and making is complex. The increase of people and goods moving across the world and the sophistication of information technology means that we now live in multiple time zones and domains. Transience and instability are becoming one of the defining conditions of the twenty first century (Papastergiadis, 2017, p.17). Consequently, how designers/artists find ways to negotiate identity and meaning in their relationship to place through textile making continues to be just as pertinent to society today than ever (Hemmings, 2015, p. 12).

The author's relationship to place has been informed by personal lived experience of diaspora when Heffer's family left Chile to come to Australia in the early seventies. The memory of assimilating to a new country is one of being suspended between two cultures. As an immigrant in her adopted place of abode, Australia, Heffer is conscious of the political sensitivities that go with being a non-indigenous practitioner. The experience of diaspora has imparted an understanding of place as being transitory in nature rather than having a claim over or ownership of. Rather Heffer's ( $p$ )lace marking is a reflection on impermanence. A unique lace making process offers Heffer a procedure to find location amidst the fluid conditions of our times giving expression to the transient nature of the world around us (see Figures 7 and 8). Thus, an alternative lace structure is explored as a metaphor for the permeable boundaries and thresholds we collectively navigate and move through today (Millar, 2011, p. 7). The writing of Italo Calvino titled Invisible Cities resonates with Heffer's reflective making process. In this story, the inhabitants of a city weave strings of communication to mark a relationship of family, trade, authority and agency (Calvino, 2012). When the strings are too dense to pass through they move on leaving behind a suspended web of threaded lace cities. Like the life of Octavia's inhabitants, the nets we build have a finite existence, they will only last so long. Today the implications of Calvino's narrative are brought to light through Covid 19 in a world dealing with an unprecedented pandemic. As its global citizens, we watch stunned by the empty abandoned spaces and cities we once wove so freely through. 

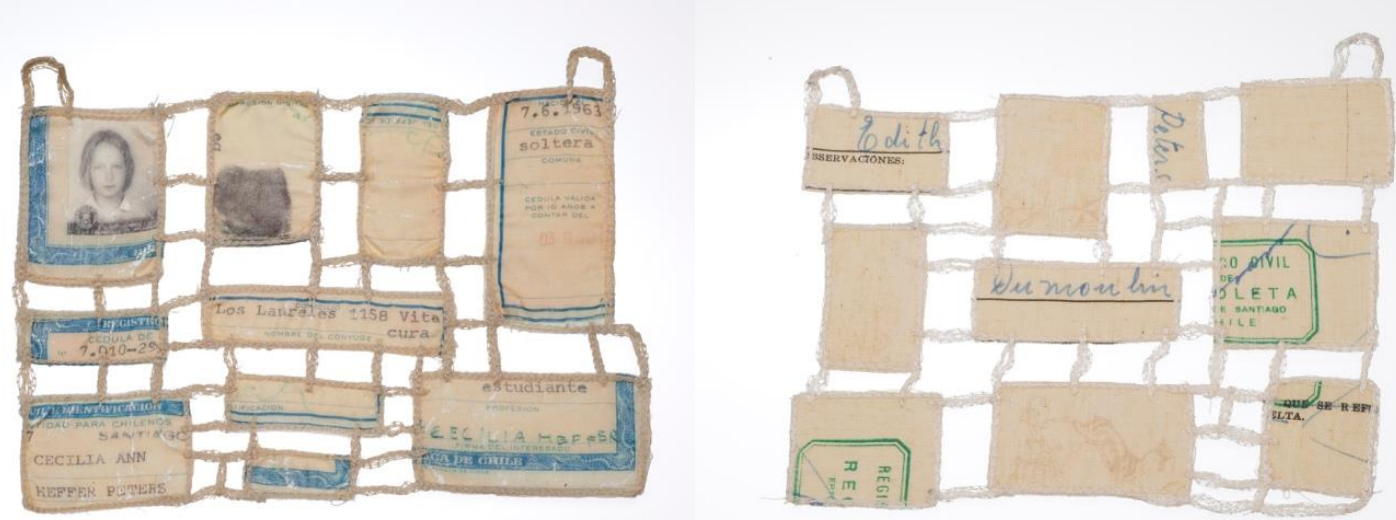

FIGURE 7 And 8. Heffer, Soltera (figure 7). Heffer, and Madre (figure 8). Both are part of a suite of works titled Lace Narratives exhibited at the Damien Minton Gallery Sydney 2010. Materials photo transfer, linen, machine stitching on a soluble substrate. Photo credit Paul Pavlou

\section{Research methods: the site, the studio, stitching as walking}

How does a textile designer engage with textile thinking to explore alternative methods for lace making? The author starts with considering how lace is defined through a patterning of positive and negative space (Shepherd, 2007, p.7). It's unique open structure gives the lace it's ethereal qualities it is so famous for. To design a lace requires the designer to be mindful of how to create the conditions for ethereality to take ( $p$ )lace. To do this Heffer engages in textile thinking processes whereby she visualizes how various layers will merge together to create an ephemeral lace. In this way visualizing a lace-scape is a form of 'lace thinking in the air'.

Initially considerable time is spent walking the landscape/site. Walking becomes a methodology, a tool for tuning into the layers of the environment in an embodied way (Crosby, Vanni, 2020, p.332). The walking is open to happenstance, it takes the form of wandering/wayfaring over the landscape with no particular route to follow. Time spent in the site is procedural, Heffer's observation through walking and ritual of collecting serves as a token attachment to place holding the traces of its origin (Massumi, 2013, p.185).
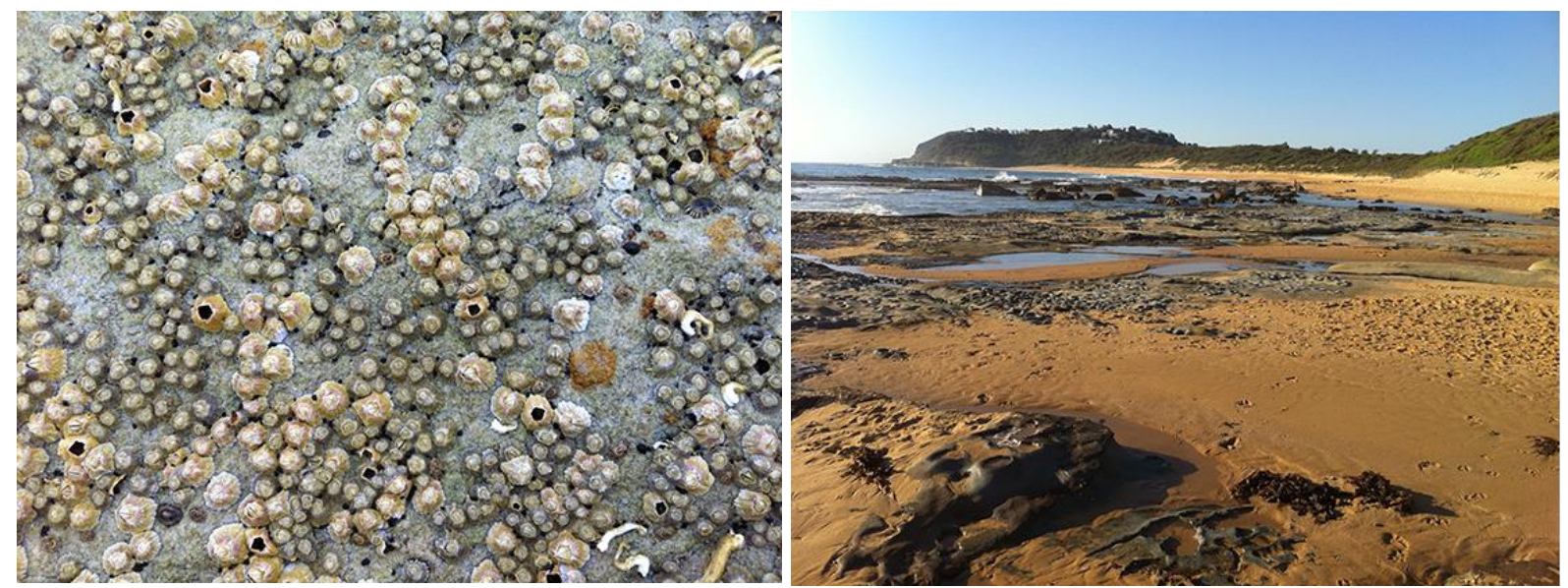

FIGURE 9 AND 10. Mollusc formations on rock (figure 9). Wamberal Beach, Central Coast NSW Australia (figure 10).

Photo taken by author 

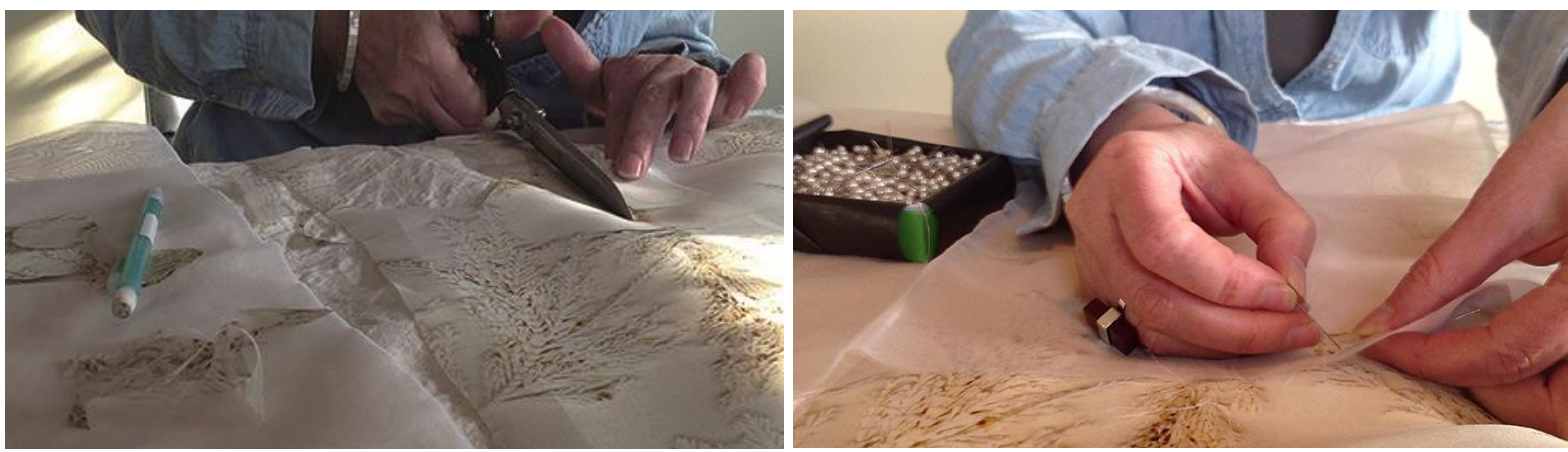

FIGURE 11 AND 12. Cutting digitally printed silk coral (figure 11). Pinning cut circles (figure 12). All photos taken by author

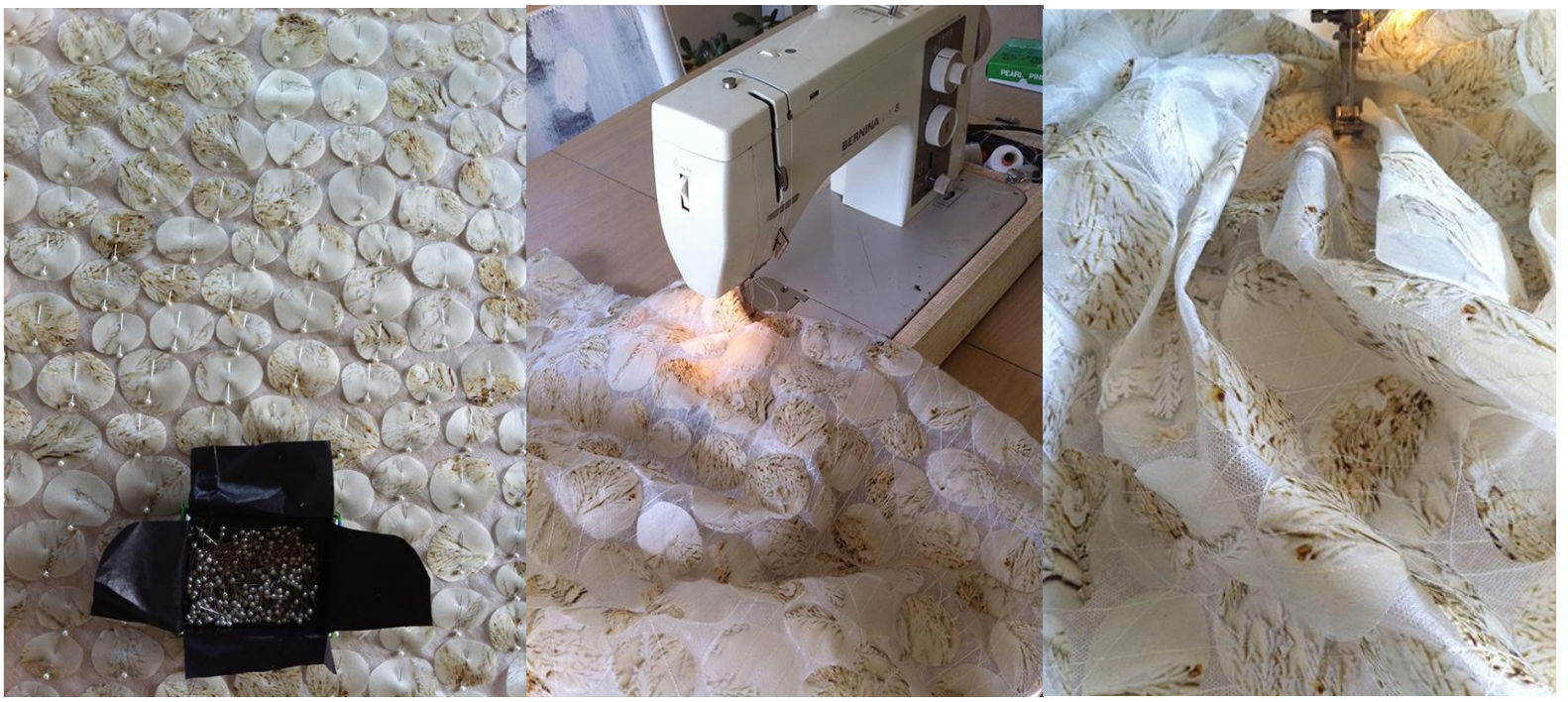

FIGURE 13,14 AND 15. Pinned silk cut circles (figure 13). Machine stitching circles onto a soluble base (figures 14 and 15).

On the walks, something may attract attention such as the materiality of a coral washed up on the shore or shredded office documents found in a workplace. Photographs and videos stop and record these curiosities encountered along the way which are taken back to the studio to inform the lace making process (see Figures 9 and 10). In the studio, the nature of the lace making is immersive and meditative. To create a lace Heffer works with the collected material either directly or through digital printing (see Figure 11). The surface of the lace work is designed to have no focal point so that the viewer's eyes wander across a visual plane. To do this, Heffer consciously engages with a disruptive patterning method to create abstraction (Jefferies, 2012, p.125). The image is deconstructed into fragments through repetitive cutting. The material fragments are then pinned selectively onto a soluble backing to create a patterned textural surface (see Figures 11, 12 and 13). Once in (p)lace they are fixed onto their new terrain through repetitive machine stitching. The terrain is impermanent as it will eventually be immersed into water to dissolve leaving behind a network of stitches (foot steps). The action of the sewing machine replaces walking with stitching, its movement of line making is akin to the act of drawing, a gestural form of knowledge making (Ingold, 2007, p.2). As Heffer drives the sewing machine over stretches of a soluble backing (an impermanent terrain) she is creating a lace network of pathways back and forward (see Figures 14 and 15). The stitched line in this instance is a walking of threads, its trails mark (p)lace holding the presence of its maker (Sennett, 2008, p.120). 


\section{THEORETICAL FRAMING: LACE AND SPACE Smooth and striated space}

The machine lace structures Heffer has developed through her practice depart from traditional lace structures as seen in as Bobbin or Embroidered Laces (historically known as stitches in the air). By comparison the machine stitching process is like a free form of weaving outside the restrictions of a loom. Like a shuttle on a loom the rhythm of the sewing machine first weaves a grid of interlocking warp and weft threads to create a base to hold found or printed material (see Figure 15). Once the initial structure is created the stitching lines go off grid wayfaring over the surface in a cross hatching formation (see Figure 16). The movement fills the spaces in between the imprinted fragments/motifs building bridges between positive and negative space. When the stitching is complete the piece is submerged into water which dissolves the soluble substrate backing (see Figure 17). In this moment, a material transformation takes ( $p$ )lace as the backing disappears the material fragments float to the surface suspended in a novel threaded lace network.
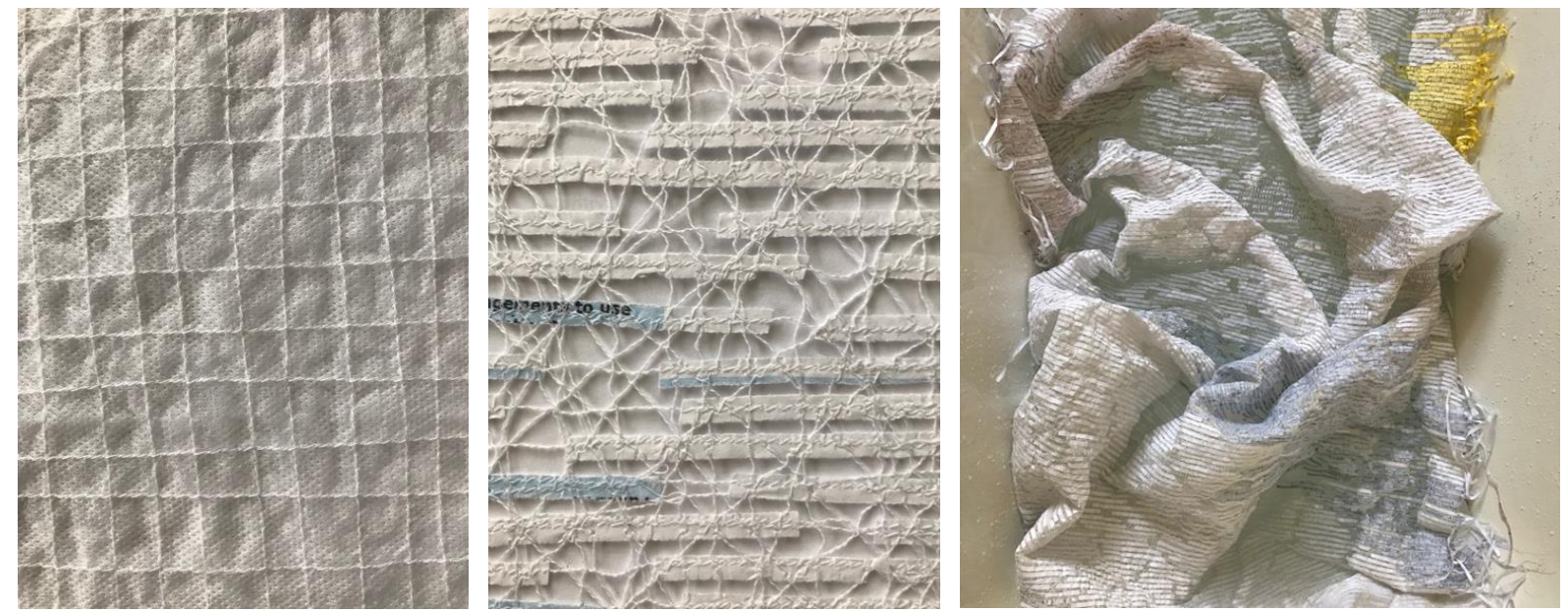

FIGURE 15,16 AND 17. Stitched grid on soluble backing (figure 15). Cross hatch stitching over grid (figure 16). The final stage of the process involves the lace being immersed into water to dissolve the soluble backing (figure 17)

The theories of French philosophers Giles Deleuze and Félix Guattari on smooth (infinite) and striated (fixed) space as being nomadic and sedentary have offered Heffer a way of reflecting through her lace making practice. To illuminate their theories woven (warp and weft) and felted textile structures are used as a metaphor to propose that striated (fixed) and smooth (infinite) space are not equal opposites (Deleuze, Guattari, 2012). On reflection, Heffer's lace structure combines both striated (fixed) and smooth (infinite) space. Each have a distinctive role yet merge together to create a contemporary remarking of ( $p$ )lace. As described above the lace grid for example is composed of a warp and weft structure (see Figure 15). It serves as a structural base to hold the material fragments. The grid structure in this case represents a striated (fixed) space. For Heffer the grid serves as a metaphor for material knowledge that is grounded in lace making histories. These material histories are fixed in time, serving as a valuable design source to reimagine new lace possibilities. In contrast, the cross-hatch stitching over the grid represents smooth and infinite space and is nomadic in nature (see Figure 16). It is similar to a non- woven felt structure whereby the fibers/stitches extend in all directions. For Heffer this free style stitching is a form of open wayfaring/knowledge making in that it moves away from traditional lace making paths to search out new material ground (Ingold, 2007, p. 101). The structures are dependent and independent of and on each other. They share a common goal which is to construct a patterning of positive and negative space in which the conditions for ethereality can occur.

In the final stage of the process the two structures the grid and the cross-hatch merge together into a delicate lace. As described above, when the final stitched piece is submerged into water the soluble substrate backing dissolves and a new lace surface emerges much like a photographic image 
processed in a dark room (see Figure 17). Without its backing the lace reveals a network of stitched traceries giving both new material form and expression to traditional embroidered laces referred to as punto en aire, 'stitches in the air'.

\section{THE COLLABORATION: METHODS, DISCOVERIES, REFLECTION}

The following films explore notions of striated and smooth space in a digital space through the medium of Animation. Over the course of a year the collaborators introduced Heffer's lace samplers into a digital space testing various opacities, layers, rotations, angles and speeds. These were compiled into small film studies which eventually made up the final animation stitches in the air. To analyse the data Heffer adopted a reflective research methodology known as intentional noticing, which offers a methodical approach to practice based research (Schön, 1991; Mason, 2002). Shifts in thinking, insights and discoveries have been collected through photographs, scans, film, reflective journaling, recorded conversations in voice memo and noted in email exchange. The three animation exercises that have been selected for discussion are as follows

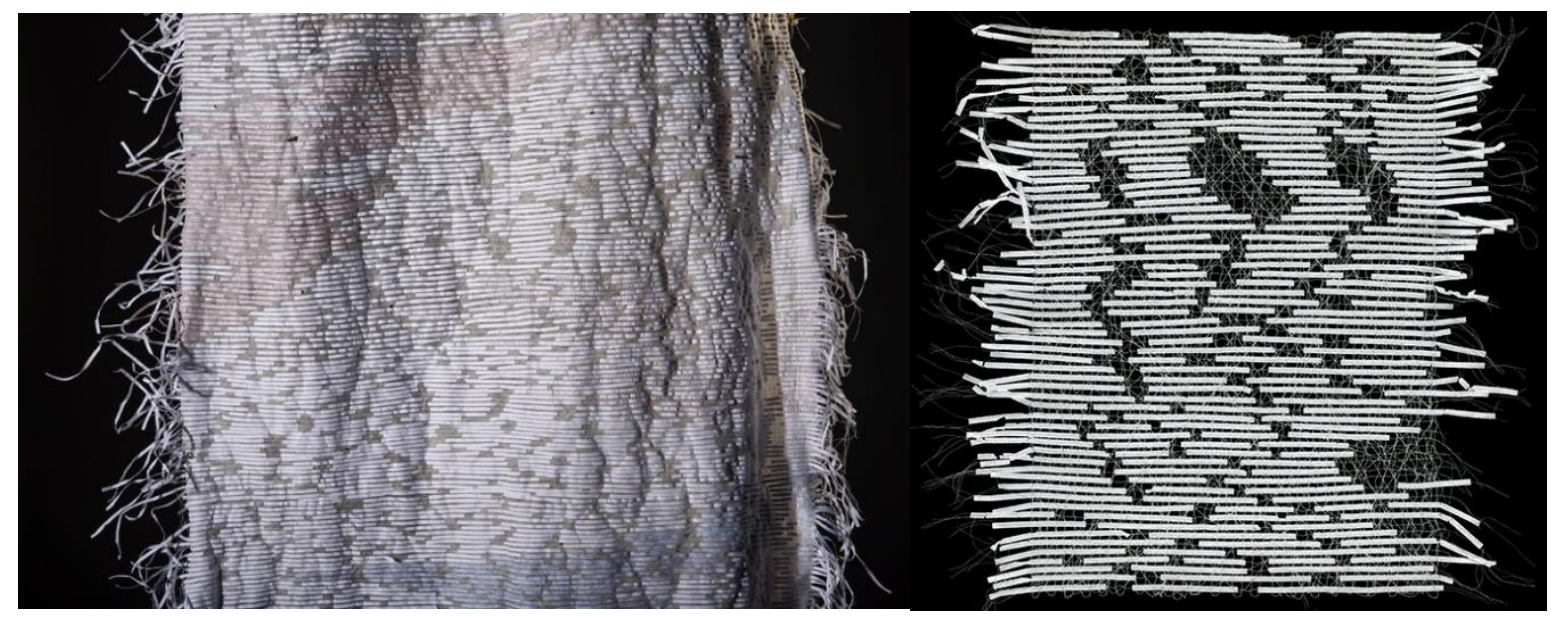

FIGURE 18 AND 19. Section of Data Lace photographed against a black ground (figure 18). Scan of a sampler (figure 19). Photo credit Paul Pavlou

\section{First Exercise: 3D Compilation Lace Movie / 2nd April 2019 (30 seconds)}

To start the collaboration, Heffer was introduced to the animation program to learn its capacities. Gascoigne's disciplinary experience steered the collaboration away from the trap of getting seduced by the technology and creating 'a bunch of effects for the sake of it'. To avoid this the collaborators agreed that the aesthetic of the lace itself did not need to be tampered with. They set out to work within a simple parameter, the options were limited to layering, rotation, speed, opacity, no color was introduced. The length of the animations was to be thirty seconds to a minute. Gascoigne suggested to use a black ground to scan the white lace samplers. This simple shift (Heffer up to this point had only photographed her work on a white ground) heightened the material language of the lace in a new way highlighting subtle intricacies and structural properties such as threads, open grids, edges, lines, stitches and shredded office documents and data (see Figure 18). The scan flattened the lace giving it a strong graphic quality in which the contrast between the material shredded data and the spaces in-between the line work were accentuated. This gave a new reading of the inter-relationships that make up the lace which in turn will serve to inform new work. Heffer observed that pools of spaces irregularly broke up the surface revealing the combination of structures the grid (fixed space) and the cross-hatching structure (smooth space) within the one lace work (see Figure 19).

The next step introduced movement to the lace. Five lace samplers were suspended above each other at equal distance apart to form a layered lace unit (see Figure 20). The floating layers in black 
space provided a new way to respond to and engage with her lace work. The introduction of movement to the laceworks opened new spatial thinking. The zoom option allowed the author to take a mental journey between each layer travelling through micro and macro views of unfolding data assemblages (Sennett 2008). To Heffer the moving layers in space visualized/materialised the abstract process of textile thinking.

When I first saw the test video, it was an incredible revelation. The suspended lace unfolding in space was aesthetically entrancing in a way I had not experienced before. The medium of animation allowed me to viscerally experience materiality in a new way, it enabled me to reside in the spaces in between the lace and move through the micro structure of the lace itself. It opened up a new imaginary world where I was flying through and around Calvino's threaded lace cities. (Heffer, journal entry, June 2019)

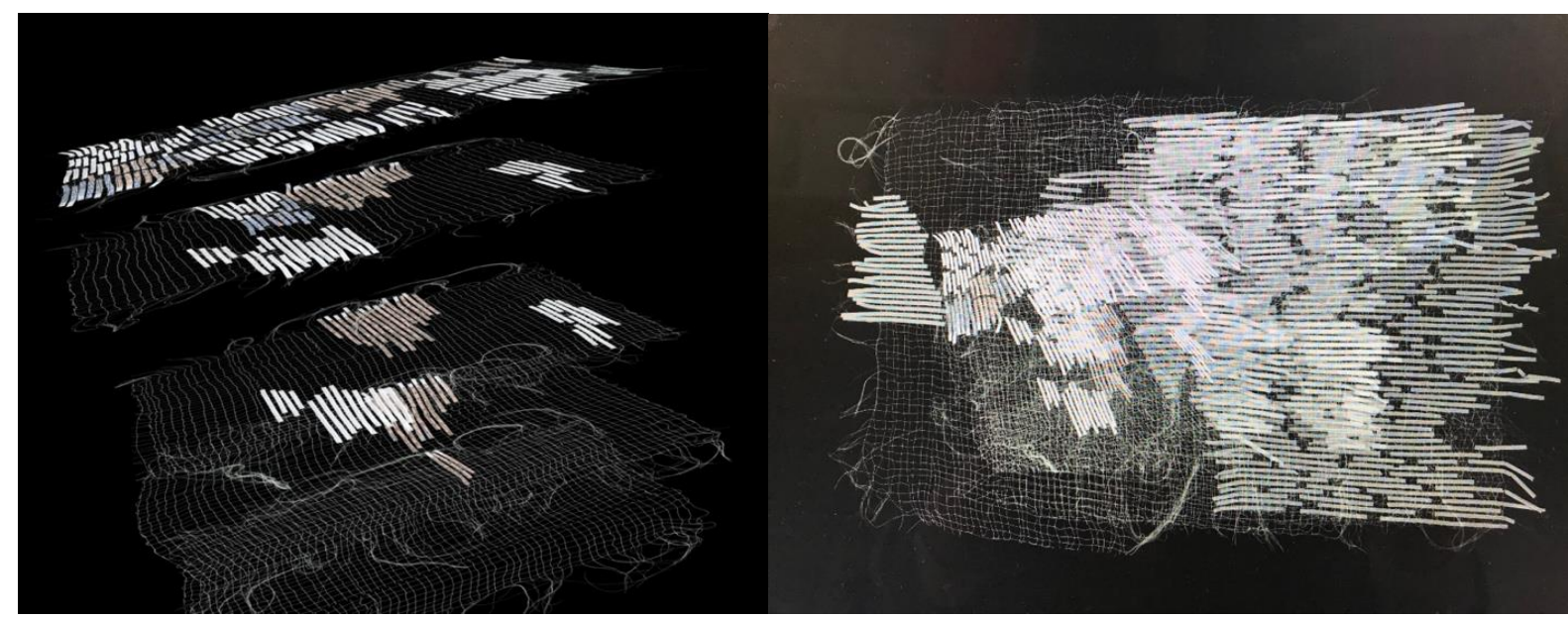

FIGURE 20 AND 21. Screen shot of 5 lace samplers, Test 1 (figure 20). Screen shot of Test 2 with 5 lace layers rotating in addition to more introduced layering (figure 21).

\section{Second exercise: White Lace Compilation/ May 29, 2019 (20 seconds)}

In the early tests the speed of the animation became a main consideration, at first the frames were too fast and the animation became too frantic which didn't encapsulate the meditative timeless quality associated with lacemaking. To address this Gascoigne introduced a smooth camera, fading in and overlapping the lace over each other. 'To our surprise the laceworks retained their material origins. The dense layering was counterbalanced by long, still shots of individual pieces, tightly cropped compositions butted up against distant views; now we had a conversation' (Gascoigne, email correspondence, 2020) The second test was effectively a serendipitous mistake as Damian had imported the movie as a low-res output (see Figure 21). The effect this created was to heighten the delicate fragility of the lace suspended in a vast digital black space. It somehow was doing something interesting turning in the space, so we brought more lace layers into the frame and layered them behind the first rotating mini lace movie. The introduction of layering with movement was transformative and added to Heffer's experience of an extended language for lace through a new digital materiality.

Third exercise: Stitches in the air 3 -LACE IN MIDDLE OF HANDKERCHEIF - JULY 82019 (20 SECONDS) As the tests progressed the idea of borders started to feature in the conversation. The edges of the laceworks had a flow of undulating threads which was quite intriguing. What would happen if the edges of the lace were masked and isolated to highlight their movement? This prompted us to place a black square in the center of the animation as a means to frame the previous tests within a strict boundary. This had the effect of masking everything out which highlighted the feathery fringed edges moving around a blank square black space. To Heffer it looked like a contemporary doily or handkerchief so she 
suggested filling in the black center with an image of one of the laces to keep the center fixed with the edges moving around it (see Figure 22). This gave the center of the animation a space of stillness, it stopped in time while the city of lace moved around it (see Figure 23). (fringes of the lace city)

Heffer's suggestion to place a still fixed lacework into the center of the animation was an instinctive textile response however in terms of animation it is a mistake to have an image sitting entirely still on the timeline. What it did however was to make something counterintuitive happen which set up an interesting relationship with the other moving elements. This in fact mirrored the inter-relationships of striated (fixed) and smooth (infinite) space within the construction of Heffer's lace. The fixed lace center became an anchor amongst the moving background, it was like a drawing from a sketch book that had been left on screen while the rest of the material animates. The fact that the lace was placed within a square still didn't make it symmetrical which was more visually interesting, giving it angles. They found the animation started to collapse, story within a story, it started to animate itself.

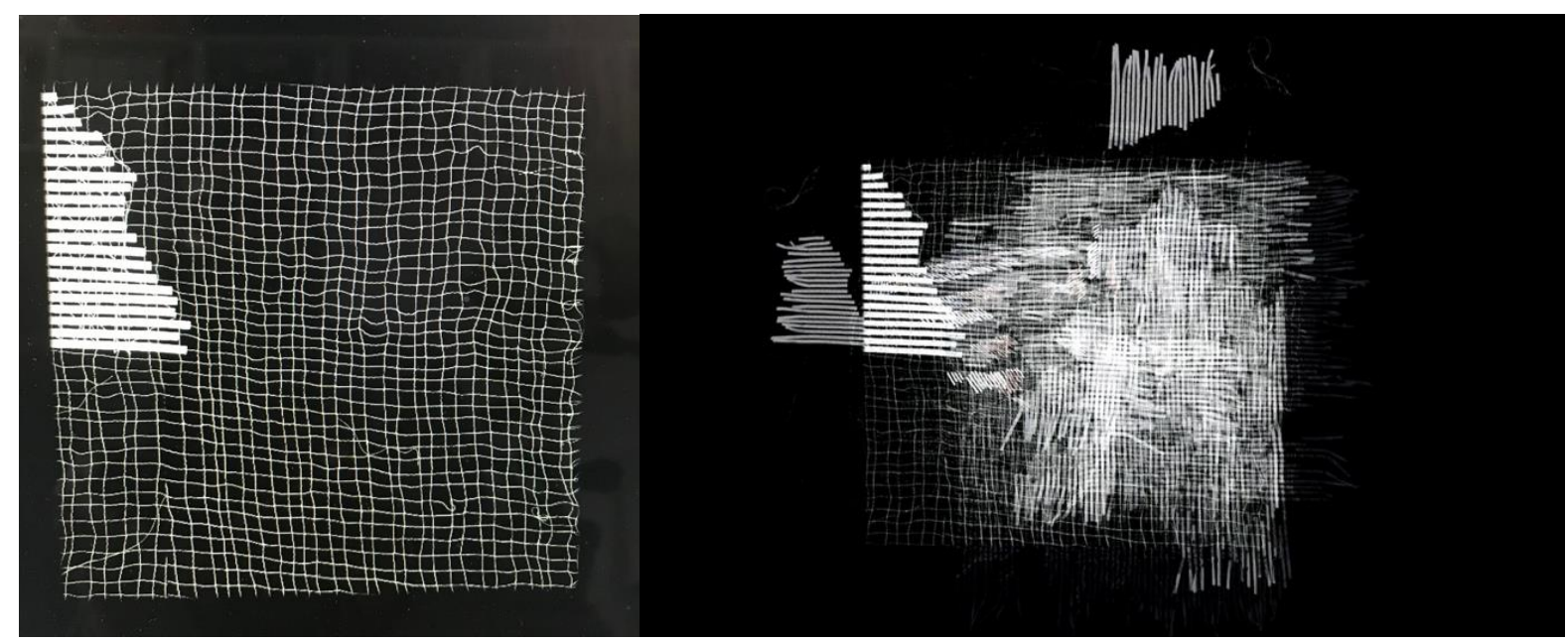

FIGURE 22 AND 23. Screen shot of cropped lace square on black background (figure 22). Screen shot of fixed cropped lace square over layered with rotating lace layers (figure 23 ).

\section{Overall reflection: an exchange of discipline idiosyncrasies}

How did the collaboration influence an animation practice? Throughout the collaboration Heffer and Gascoigne learnt about the materiality of each other's discipline. The two shared a mutual respect for preserving the handmade in a digital space. In his practice, Gascoigne advocates for a balance of the hand drawn and digital. He seeks out imperfection and accidents in drawing through remixing and recycling sequences of drawn animation often discarding his work to keep his discoveries and ideas fresh. As the two met and reviewed each animation sequence Heffer intuitively responded and made decisions (on the speed, rotation, layering, rotation) based on her implicit understanding of the material characteristics of her lace. Thus, she was instinctively lacemaking (textile thinking) in a digital space. Gascoigne found Heffer's textile thinking/methods refreshing in that her decision-making process was direct and at times counter intuitive to his own pattern of practice. Heffer could see parallels between the disciplines each having their own language which follow a set of grammatical 'material rules'. Quite naively her textile approach broke a few animation rules. One of the key 'transgressions' for Gascoigne was Heffer's introduction of the extended pause in the animation whereby a single lace was suspended as a still while the other lace layers moved around it. In animation, this normally is seen as a mistake however Heffer was happy to pause in movement which gave the effect of inviting the viewer to slow down and watch at a walking pace.

So, beyond the enjoyment of working with the lace works themselves, the collaboration affected my practice primarily by virtue of Cecilia's resistance to the lure of the digital. There seemed to be a facture continuum at work in her judgment at all times, that to stray too far from 'truth to materials' would not 
be a fruitful path. Working with someone as clear-sighted as Cecilia has reminded me that it takes enormous self-discipline for the digital maker to maintain focus, to be satisfied with something modest in construction but clear in purpose. In an age of digital addicts, the digital maker is double cursed. We need the input of material makers who trust their work as it comes. This collaboration brings me back to the importance of decisive attention, a mode of decision making which aligns with believing in the intrinsic value of the hand-made. (Gascoigne, email $25^{\text {th }}$ November 2020)

\section{CONCLUSION}

This paper has presented a unique interdisciplinary collaboration between a textile designer and an animation artist. The research enquiry sought to capture and disseminate an ephemeral lacemaking process through the medium of animation. While the digital does not replace a material practice it has brought new thinking and opened unexpected pathways for future textile exploration. The unique materiality of animation brings a nuanced language with which to craft novel expressions of ( $p$ )lace in a digital age. In turn the collaboration has influenced an animation practice to slow down and give agency to the value of the hand-made. Lace in a digital space has a lot to tell us, it invites us to slow down and push against the digital speed of our lives (Dorst, 2007, p.7).

The materiality and subtle voice of the lace prevailed throughout the experiment gently reminding us of our collective condition of impermanence and change. Heffer found it a curious push and pull between two mediums that engage with time in completely opposite ways. The speed and agility of the digital medium afforded a lighter visceral experience of lacemaking in space. In this experiment, the digital moved beyond being a tool for speed and efficiency to a method for abstracting and expanding the craft of lace making (Carnie, 2007, p.20). Viewing the lace in motion was a revelation taking Ingold's gesture of the line as knowledge making into a new terrain.

The process became less about sequential thinking which traditionally follows a linear production system and more about abstract spatial relationships. The experiment extended interrelationships between striated (fixed) and smooth (infinite) space in a digital space (Deleuze, Guattari, 2012). As a result, a textile designer learnt how to give traditional embroidered laces known as stitches in the air a contemporary voice. (P)lace has been reimagined as a timeless digital lace-scape echoing the impermanence of a Calvino abandoned lace city, a scaffolding of suspended threads (Calvino, 2012). These ephemeral lace environments were created through programming numeric data, as numbers are infinite we can propose that these lace environments have materialised an infinity of impermanence. (Infinity as a state of impermanence)

\section{ACKNOWLEDGEMENTS}

Stitches in the air was created on the UTS campus which stands on the ancestral land of the Gadigal People of the Eora and People of the Dharug Nation. I would like to pay respect to the Elders both past and present, acknowledging them as the traditional custodians of knowledge for these lands. Thank you to Damian Gascoigne for his generous expertise throughout this collaboration and to Professor Robyn Healy and Dr Scott Mayson for their ongoing support as supervisors in my PhD candidature at RMIT, in the School of Fashion and Textiles. 


\section{REFERENCES}

Briggs-Goode, A., \& Dean, D. (2013). Lace: Here: Now. Black Dog Publishing.

Calvino, I. (2012). Invisible Cities. In J. Hemmings (Ed.), The Textile Reader (pp.123-124). Bloomsbury. (Reprinted from Invisible Cities, by I. Calvino, 1972, Harcourt Publishing Company)

Carnie, B. (2007). Digitising Positive + Negative Space: A Case Study. In C. Heffer (Ed.), Lace: Contemporary Textiles: Exhibition + New Works: Cecilia Heffer. (pp. 18-21). DAB DOCS.

Crosby, A., \& Vanni, I. (2020). The not-yet-tropical: mapping recombinant ecologies in a Sydney suburb. Visual Communication Journal 19(3), 331-352. https://doi.org/10.1177\%2F1470357220915652

Deleuze, G., \& Guattari, F. (2012). 1440: The Smooth and The Striated. In J. Hemmings (Ed.), The Textile Reader (pp.179-181). Bloomsbury. (Reprinted from, A Thousand Plateaus: Capitalism and Schizophrenia, pp. 474-477, trans. B. Massumi, 1987, University of Minnesota Press)

Dorst, K. (2007). Lace Speaks to Us Again. In C. Heffer (Ed.), Lace: Contemporary Textiles: Exhibition + New Works: Cecilia Heffer. (pp. 7-9). DAB DOCS.

Dorst, K. (2015). Frame Creation and Design in the Expanded Field. She Ji: The Journal of Design, Economics, and Innovation, 1(1), 22-33. http://dx.doi.org/10.1016/j.sheji.2015.07.003

Heffer, C. (2015). Lace Narratives: A Monograph, 2005 - 2015. UTS ePress. https://doi.org/10.5130/978-09924518-6-8

Hemmings, J. (Ed.). (2012). The Textile Reader. Berg Publishers.

Hemmings, J. (Ed.). (2015). Cultural Threads: Transnational Textiles Today. Bloomsbury.

Igoe, E. (2013). In Textasis: Matrixial Narratives of Textile Design, [Doctoral dissertation, Royal College of Art]. ProQuest Dissertations Publishing. http://search.proquest.com/docview/1780278821/

Ingold, T. (2007). Lines, A Brief History. Routledge. https://doi.org/10.4324/9780203961155

Jefferies, J. (2012). Pattern, Patterning. In C. Lury, \& N. Wakeford (Eds.), Inventive Methods: The Happening of the Social (pp.125-133). Routledge. https://doi.org/10.4324/9780203854921

Jefferies, J., Wood Conroy, D., \& Clark, H. (Eds.). (2016). The handbook of textile culture. Bloomsbury. https://doi.org/10.5040/9781474268684

Lean, M. H. A. (2020). Materialising data experience through textile thinking, (Publication No. 28197068) [Doctoral dissertation, Royal College of Art]. ProQuest Dissertations Publishing. https://researchonline.rca.ac.uk/id/eprint/4443

Mason, J. (2002). Researching your own practice: The discipline of noticing. RoutledgeFalmer. https://doi.org/10.4324/9780203471876

Massumi, B. (2013). Making to Place: In the Artist's Words Refracted. In C. Zegher (Ed.), Here Art grows on Trees; Simryn Gill (pp.185-225). Australia Council for the Arts, 55 $5^{\text {th }}$ Venice Biennale.

McFadden, D., Scanlan, J., Edwards, J., \& Frankel, S. (Eds.). (2008). Radical lace \& subversive knitting. Museum of Arts and Design.

Millar, L. (2011). Transparent Boundaries. In L. Millar (Ed.), Lost in Lace: Transparent Boundaries (pp. 5-12). Published by Birmingham Museums \& Art Gallery.

Nimkulrat, N., Kane, F., \& Walton, K. (Eds.). (2016). Crafting Textiles in the Digital Age. Bloomsbury. https://doi.org/10.5040/9781474285902

Orpin, E. (2015, July). Craft Modern Lace, Profiles of Contemporary Lacemakers. Uppercase Magazine, (26), 68 87.

Pajaczkowska, C. (2016). Making Known: The Textiles Toolbox - Psychoanalysis of Nine Types of Textile Thinking. In J. Jefferies, D. Wood Conroy, \& H. Clark (Eds.), The Handbook of Textile Culture (pp. 79- 94). Bloomsbury. https://doi.org/10.5040/9781474268684.ch-006 
Papastergiadis, N. (2017). Motion Fearness. In E. McEoin, S. Maldment, M. Patty, \& P. Wallis (Eds.), NGV Triennial 2017 (pp. 20 - 31). Council of Trustees of National Gallery of Victoria.

Plumley, F. (2012, March). Stitches in air: Computational craft. Artlink, 32(1), 63.

Schön, D. A. (1991). The Reflective Practioner, How Professionals Think in Action. Ashgate Publishing.

Sennett, R. (2008). The Craftsman. Yale University Press.

Shepherd, R. (2007). Lace, threading a history. In C. Heffer (Ed.), Lace: Contemporary Textiles: Exhibition + New Works: Cecilia Heffer. (pp. 10-13). DAB DOCS.

Shepherd, R. (2011). Preface. In L. Ward \& R. Shepherd, (Eds.), Make Lace Not War: Powerhouse Museum International Lace Award (pp.9). Powerhouse Publishing.

Sudo, R. (2011). Tanabata Lace. In L. Millar, (Ed.), Lost in Lace: Transparent Boundaries (pp.100-101). Published by Birmingham Museums \& Art Gallery.

Ward, L. (2012, March). Openwork Patterns. Artlink, 32(1), 34-37.

Wilson, A. (2008). Topologies, Artists Statement. https://www.annewilsonartist.com/topologies-credits.html 